improved durability and performance relative to previous VADs. Our major rationale for choosing the HeartWare HVAD was its relatively small size and ability to be contained within the pericardium, thus eliminating the potential need to create a pocket or rotate the pump configuration. In addition, the device's integrated inflow cannula could decrease the chance of inflow obstruction related to the abnormal position of the ventricles in CC-TGA. TEE guidance ensured successful selection of the optimal insertion site for the VAD inflow cannula.

In summary, we report a case of successful HeartWare HVAD implantation in a patient with CC-TGA to support the function of the RV (systemic ventricle).

\section{References}

1. Graham TP Jr, Bernard YD, Mellen BG, Celermajer D, Baumgartner H, Cetta F, et al. Long-term outcome in congenitally corrected transposition of the great arteries: a multi-institutional study. J Am Coll Cardiol. 2000;36:255-61.

2. Beauchesne LM, Warnes CA, Connolly HM, Ammash NM, Tajik AJ Danielson GK. Outcome of the unoperated adult who presents with congenitally corrected transposition of the great arteries. J Am Coll Cardiol. 2002;40:285-90.

3. Stewart AS, Gorman RC, Pocchetino A, Rosengard BR, Acker MA. Left ventricular assist device for right side assistance in patients with transposition. Ann Thorac Surg. 2002;74:912-4.

4. Gregoric ID, Kosir R, Smart FW, Messner GN, Patel VS, La Francesca S, et al. Left ventricular assist device implantation in a patient with congenitally corrected transposition of the great arteries. Tex Heart Inst J. 2005;32:567-9.

5. Joyce DL, Crow SS, John R, St Louis JD, Braunlin EA, Pyles LA, et al. Mechanical circulatory support in patients with heart failure secondary to transposition of the great arteries. J Heart Lung Transplant. 2010;29:1302-5.

\title{
The role of the total artificial heart in the treatment of post-myocardial infarction ventricular septal defect
}

\author{
Awais Ashfaq, MD, Dawn E. Jaroszewski, MD, MBA, FACS, Octavio E. Pajaro, MD, FACS, and \\ Francisco A. Arabia, MD, MBA, FACS, Phoenix, Ariz
}

Post-myocardial infarction ventricular septal defect (VSD) can be a fatal complication. Mechanical support to stabilize the patient until repair or transplant may be necessary, because emergency operative repair carries a mortality as high as $60 \% .^{1-3}$ The CardioWest Total Artificial Heart (TAH-t; SynCardia Systems, Inc, Tucson, Ariz) has been used successfully to replace the failing heart as a bridge to transplant. ${ }^{4}$ We report the cases of the first 2 patients treated with TAH-t implantation for unstable cardiogenic shock resulting from post-MI VSD rupture.

\section{CLINICAL SUMMARIES \\ Patient 1}

A 68-year-old man was transferred to our institution in extremis after an anterior MI and left anterior descending stent 2 placement weeks previously. Evaluation by echocardiography showed a large pericardial effusion, a 22-mm apical VSD, and biventricular failure. The patient had deterioration to cardiogenic shock (systolic blood pressures less than 75

\footnotetext{
From the Division of Cardiothoracic Surgery, Department of Surgery, Mayo Clinic Arizona, Phoenix, Ariz

Disclosures: Authors have nothing to disclose with regard to commercial support. Received for publication Sept 11, 2012; revisions received Oct 12, 2012; accepted for publication Nov 6, 2012; available ahead of print Dec 10, 2012.

Address for reprints: Dawn E. Jaroszewski, MD, MBA, FACS, Division of Cardiothoracic Surgery, Mayo Clinic Arizona, 5777 E Mayo Blvd, Phoenix, AZ 85054 (E-mail: Jaroszewski.dawn@mayo.edu).

J Thorac Cardiovasc Surg 2013;145:e25-6

$0022-5223 / \$ 36.00$

Copyright (C) 2013 by The American Association for Thoracic Surgery

http://dx.doi.org/10.1016/j.jtcvs.2012.11.018
}

$\mathrm{mm} \mathrm{Hg}$, pulmonary arterial pressure 50/20 mm Hg, central venous pressure of $16-21 \mathrm{~mm} \mathrm{Hg}$, and pulmonary wedge pressure of $31 \mathrm{~mm} \mathrm{Hg}$ ) and was intubated and transferred to our institution on maximal pressor support. At arrival, emergency venoarterial extracorporeal membrane oxygenation (ECMO) was instituted through the femoral vessels, and the patient's condition was allowed to stabilize for 24 hours. The patient underwent surgery for possible repair and device support; however, because of extensive myocardial damage and poor function, the decision was made intraoperatively for TAH-t placement. The patient was extubated within 24 hours and supported for 76 days until heart transplant. He had an uncomplicated hospital course and was discharged 2 weeks after transplant. At 3 years of follow-up, the patient remains in excellent condition.

\section{Patient 2}

A 65-year-old woman with a medical history significant for diabetes mellitus type 2, hypertension, hyperlipidemia, and scleroderma was admitted to outside hospital for an acute inferior MI. She was taken for emergency cardiac catheterization and had 2 stents placed in the proximal and mid right dominant coronary artery. On the next day, she became dyspneic and hypotensive. Physical evaluation noted a new heart murmur, and echocardiography revealed a large inferior base VSD of $14 \mathrm{~mm}$ with biventricular failure. The patient was intubated, an intra-aortic balloon pump was placed, and pressor support was maximized. The patient's condition continued to deteriorate, and she was transferred to our 
institution and stabilized with femoral venoarterial extracorporeal membrane oxygenation. The patient was deemed a transplant candidate and taken to the operating room 4 days later for mechanical circulatory support. Intraoperative evaluation noted extensive bilateral myocardial necrosis and friability, including the left apex, septum, and a large portion of the right ventricle. The decision was made for TAH-t placement. On postoperative days 0,1 , and 3 , the patient required reexploration and evacuation of hematoma for bleeding and mediastinal hematoma. She continued to progress to multiorgan failure, coagulopathy, and vasodilatory shock despite multipressor support. Evidence of sepsis, including bilateral pneumonia and lactic acidosis, led to discontinuance of support 9 days after TAH-t implantation.

\section{DISCUSSION}

VSDs are rare, life-threatening complications that occur after MI in $1 \%$ to $2 \%$ of patients. ${ }^{1}$ As many as $90 \%$ of patients would die without intervention; however, mortality with emergency surgical or percutaneous repair is still greater than $50 \%{ }^{1}$ Patients who have cardiogenic shock and biventricular failure develop require mechanical support for stabilization until definitive repair or transplant can be performed. Implantable left ventricular assist devices have been successfully used as a bridge to transplant after postMI VSD. ${ }^{3}$ Securing the inflow cannula to infarcted apical myocardium can be technically difficult, and post-MI ventricular arrhythmias may complicate left ventricular assist device management. Severe valvular insufficiency and post-MI extensive left ventricular myocardial loss with poor function may favor replacement of both ventricles.

The TAH-t is a pneumatic, pulsatile pump that replaces the patient's ventricles and native valves. Implantation of the TAH-t has been shown to improve outcomes in unstable patients in end-stage cardiogenic shock by providing immediate hemodynamic stabilization and end-organ perfusion until cardiac transplant can occur. Survivals to transplant with the TAH-t as great as $79 \%$ have been reported, ${ }^{4}$ comparable to biventricular support survival of $56 \%$ at 6 months. ${ }^{5}$ Use of the TAH-t currently obligates the patient to undergo a transplant, and every effort should be made to preserve the patient's own myocardium. All mechanical support devices possess inherent risk factors, including infection, thromboembolism, and hemorrhage.

We present the first 2 cases of patients with post-MI VSD rupture with end-stage cardiogenic shock to undergo TAH-t placement. TAH-t support is an alternative option to biventricular support devices for critically unstable patients with post-MI VSD and extensive ventricular myocardial loss. Mortality was $50 \%$ in this small series, which underlines the complexity of predicting outcomes in this patient population.

\section{References}

1. Arnaoutakis GJ, Zhao Y, George TJ, Sciortino CM, McCarthy PM, Conte JV. Surgical repair of ventricular septal defect after myocardial infarction: outcomes from the Society of Thoracic Surgeons National Database. Ann Thorac Surg. 2012;94: 436-43; discussion 443-4

2. Conradi L, Treede H, Brickwedel J, Reichenspurner H. Use of biventricular mechanical support in a case of postinfarction ventricular septal rupture as a bridge to surgery. Ann Thorac Surg. 2009;87:e37-9.

3. Faber C, McCarthy PM, Smedira NG, Young JB, Starling RC, Hoercher KJ. Implantable left ventricular assist device for patients with postinfarction ventricular septal defect. J Thorac Cardiovasc Surg. 2002;124:400-1.

4. Copeland JG, Smith RG, Arabia FA, Nolan PE, Sethi GK, Tsau PH, et al. Cardiac replacement with a total artificial heart as a bridge to transplantation. $N$ Engl J Med. 2004;351:859-67.

5. Cleveland JC Jr, Naftel DC, Reece TB, Murray M, Antaki J, Pagani FD, et al. Survival after biventricular assists device implantation: an analysis of the Interagency Registry for Mechanically Assisted Circulatory Support database. J Heart Lung Transplant. 2011;30:862-9.

\title{
Left ventricular vegetations: A rare manifestation of Libman-Sacks endocarditis
}

\author{
Naritomo Nishioka, MD, Naoto Morimoto, MD, PhD, Masato Yoshida, MD, PhD, and \\ Nobuhiko Mukohara, MD, PhD, Himeji-city, Japan
}

\footnotetext{
From the Department of Cardiovascular surgery, Hyogo Brain and Heart Center at Himeji, Himeji-city, Japan.

Disclosures: Authors have nothing to disclose with regard to commercial support.

Received for publication Oct 31, 2012; accepted for publication Nov 9, 2012; available ahead of print Dec 10, 2012

Address for reprints: Naritomo Nishioka, MD, Cardiovascular Surgery, Hyogo Brain and Heart Center at Himeji, 520 Saisho-kou, Himeji-city, Hyogo 670-0981, Japan (E-mail: naritomo.n@nifty.com).

J Thorac Cardiovasc Surg 2013;145:e26-8

$0022-5223 / \$ 36.00$

Copyright (C) 2013 by The American Association for Thoracic Surgery

http://dx.doi.org/10.1016/j.jtcvs.2012.11.034
}

Libman-Sacks endocarditis, first described by Libman and Sacks ${ }^{1}$ in 1924, is the pathognomonic valvular lesion of systemic lupus erythematosus or antiphospholipid antibody syndrome that may develop on the endocardial surface of the heart. These lesions have a propensity toward formation on the left valves, particularly the ventricular surface of the mitral valve. We report the case of a 26 -year-old woman without a history of cardiac disease who was seen for an atypical form of Libman-Sacks endocarditis. The disease progressed in an 